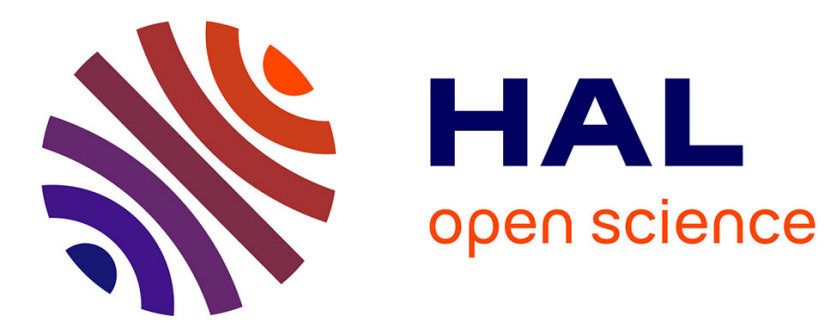

\title{
Sustainable agriculture: possible trajectories from mutualistic symbiosis and plant neodomestication
}

Marie Duhamel, Philippe Vandenkoornhuyse

\section{To cite this version:}

Marie Duhamel, Philippe Vandenkoornhuyse. Sustainable agriculture: possible trajectories from mutualistic symbiosis and plant neodomestication. Trends in Plant Science, 2013, 18 (11), pp.597-600. 10.1016/j.tplants.2013.08.010 . hal-00932183

HAL Id: hal-00932183

https://hal-univ-rennes1.archives-ouvertes.fr/hal-00932183

Submitted on 16 Jan 2014

HAL is a multi-disciplinary open access archive for the deposit and dissemination of scientific research documents, whether they are published or not. The documents may come from teaching and research institutions in France or abroad, or from public or private research centers.
L'archive ouverte pluridisciplinaire HAL, est destinée au dépôt et à la diffusion de documents scientifiques de niveau recherche, publiés ou non, émanant des établissements d'enseignement et de recherche français ou étrangers, des laboratoires publics ou privés. 
1 Sustainable agriculture: possible trajectories from mutualistic

2 symbiosis and plant neodomestication

3

4 Marie Duhamel $^{1,2}$, Philippe Vandenkoornhuyse ${ }^{1}$.

5

$6 \quad{ }^{1}$ Université de Rennes I, CNRS UMR6553 EcoBio, Campus Beaulieu, F-35042

7 Rennes, France.

$8 \quad{ }^{2}$ Institute of Ecological Science, Vrije Universiteit, 1081 HV Amsterdam,

9 Netherlands

10 Corresponding author: Prof P. Vandenkoornhuyse

11 (philippe.vandenkoornhuyse@univ-rennes1.fr) 
15 Food demand will increase concomitantly with human population.

16 Food production therefore needs to be high enough and, at the same time, minimize damage to the environment. This equation cannot be solved with current strategies. Based on recent findings, new trajectories for agriculture and plant breeding which take into account the below-ground compartment and evolution of mutualistic strategy, are proposed in this opinion article. In this context, we argue that plant breeders have the opportunity to make use of native Arbuscular ecologically intensive agriculture.

A sustainable food production ?

Feeding the world and securing access to food are both major social and

31 scientific issues. Food crises have often occurred in the past. In recent years,

32 the rapidly increasing demand for food (i.e., for human populations and

33 livestock) along with biofuels has led to food price volatility [1]. Furthermore, 34 recent work suggests that food crises are exacerbated by global warming. It 35 has been clearly indicated that agricultural productivity has declined world36 wide as a consequence of the hottest summers experienced in the recent past, 37 and according to different global warming scenarios “... the hottest seasons on 
record will represent the future norm in many locations ..." [1]. Human

39 population is continuously increasing, but expected to peak before the end of

40 the century, with 10 billion people before 2100 [2]. Contrary to common

41 assumption, non-linearities between population expansion and environmental

42 degradation are likely to increase disproportionately rapidly [3]. Human

43 population expansion will be coupled with an increased demand for space,

44 water and food. These demands will therefore be accompanied by urban and

45 cropland expansion, and more than $10^{9}$ hectares of natural ecosystems are 46 likely to be lost by 2050 [4]. This represents collateral damage for the 47 environment because cropland expansion can only be achieved by replacing 48 non agricultural, mainly forested areas. According to recent studies, agricultural 49 production will have to expand by about $100 \%$ during the $21^{\text {st }}$ century to satisfy 50 forecasted world demands [5]. At the same time, agriculture is a major threat 51 to the environment eventually leading to a decline in biodiversity and related 52 ecosystem services, including degradation of soil and water quality [6].

A fundamental issue for agriculture during this century is thus to confront 54 two contradictory goals, (i) the need to produce enough food to minimize 55 human malnutrition and support world population expansion and (ii) the need 56 to limit collateral damage to the environment, which can in turn negatively 57 impact agriculture. Based on recent findings about strategies in plant 58 mutualisms and plant selection, we develop new ideas in this paper and 59 suggest trajectories for a more sustainable agricultural development.

\section{Intensive vs. extensive agriculture ?}

62 The aim in intensive agriculture is to maximize productivity per unit of surface, 
63 whereas in extensive agriculture, lower productivity yields are accepted as a

64 counterpart to less potential ecosystem damage. The main advantage of

65 extensive agriculture is that no or few inputs are required. However this is often

66 countered by a need for a larger soil area to obtain comparable production. It

67 has been shown that agricultural intensification with high yield production

68 eventually increases greenhouse gas emissions per unit surface. However,

69 much higher carbon emissions can be expected if the same production is

70 obtained by expanding low-yield farming (e.g. $[7 ; 8]$ ). Similarly, the need to

71 increase agricultural productivity to limit adverse effects on the environment

72 has also been underlined by modeling land use/land cover changes [9] and by

73 projecting possible improvements of productivity in existing agricultural areas

74 [10]. One key element which has emerged is the necessity for agricultural

75 intensification to preserve biodiversity and the related ecosystem services. As

76 developed below, new ideas for maintaining high crop productivity with lower

77 inputs have recently been put forward.

79 Crop selection from traits?

80 Since the beginning of agriculture, crops have been selected for different traits,

81 including plant productivity. The main current approach to modern plant

82 breeding is to maximize the fitness of individual plants. However other

83 contrasting breeding strategies have been suggested. One of the most exciting

84 of these new solutions would be to base plant breeding on group selection

85 rather than on individual plant fitness [11] (where group selection refers to the

86 selection '... for attributes that increase total crop yield but reduce plants'

87 individual fitness...' [11]). This would imply a completely new approach to 
selection criteria. For example, selecting for cooperative shading, which would allow a passive control of weeds, seems promising to improve yield and sustainability [11].

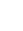

In all these breeding approaches (i.e. individual selection and group selection), however, plants are always considered as standalone entities, which is arguably a mistake. Plants are deeply dependent on mutualist microorganisms for their growth, and these can be damaged by conventional agricultural practices and current plant breeding strategies.

\section{Arbuscular mycorrhiza and consequences of agricultural practices}

The arbuscular mycorrhizal symbiosis is responsible for massive global nutrient transfer (Box 1). It is a mutualism 'that helps feed the world' [12]. Arbuscular mycorrhizal fungi, because of their functions, can be considered as key microorganisms for soil productivity.

Intensive agricultural management (i.e., conventional agriculture in Europe and North America) has exerted a high selection pressure on microorganisms through profound modification of their habitats and niches, notably brought about by tillage, the high increase of mineral nutrients, and low plant diversity (i.e., crops). Tillage, ploughing and ripping, for example, represent an intense form of soil disruption. In natural habitats, AM mutualism is not subjected to perturbations of this intensity. Such disruption leads to degradation of the hyphal network, ecological functions, and AM fungal diversity [13]. Soil nutrient availability is a strong driving influence for producing an evolved geographic structure in AM mutualism (i.e., a 
113 coevolutionary selection mosaic) [14]. As a result, soil fertilization in

114 agricultural ecosystems has had a negative impact on AM fungal functions [15]

115 and diversity [16]. Thus confounding factors, related to conventional

116 agricultural trajectories, likely act synergistically against mycorrhizal symbiosis.

118 Mutualistic strategy and agriculture

119 From a theoretical point of view, mutualisms (i.e. cooperative interactions

120 among different species) can exhibit instability: individuals potentially benefit

121 from defecting from cooperation if cooperation is costly. Organisms will

122 increase their own fitness, even if this comes to a cost of others. Kiers et al,

123 [17] have demonstrated the capacity of plants to sanction less-cooperative

124 strains (i.e. 'cheaters') through a carbon embargo. The gain in fitness for the

125 cheater is therefore reduced by this plant trait. This in itself can explain the

126 stability of this symbiosis. A similar sanction of carbon allocation has been

127 observed in the case of nitrogen-fixing nodules in leguminous plants to control

128 Rhizobium cheaters [18]. The most cooperative AM fungal symbionts transfer

129 more phosphorus to the roots when they receive more carbon [17]. Such

130 mutualism is therefore bilaterally controlled because both partners can enforce

131 the cooperation and any possible enslavement strategy is also limited. This

132 fairly explains the stability of arbuscular mycorrhizal symbiosis. In addition, the

133 main advantage for the plant to not enslave its symbionts is the access offered

134 to numerous potential functions harbored by the reservoir of soil AM fungi into

135 which the plant can tap depending on its nutritional requirements. For the

136 fungi, the main advantage of not being enslaved is to be able to maintain a

137 high level of diversity. This symbiosis is one reason for the success of plants in 
terrestrial ecosystems.

Less cooperative AM fungi do exist in nature. We can expect them to become more abundant as the diversity of AM fungi decreases because the symbiotic options offered to the plants are more limited. It has been shown that AM fungi cheaters can develop 'dealer' behavior by keeping phosphorus in polyphosphate chains and delivering it at an expensive cost for the host plant [17]. The plant's capacity to sanction cheaters is a tremendously important trait to maintain, given the fact that most mineral nutrients $(\sim 70 \%$ of the phosphorus for example) are delivered to plants by AM fungi [19] (Box 1) in 'natural' environments.

\section{New ideas for more sustainable agricultural practices by promoting}

\section{mutualisms}

Ecosystem productivity has been shown to be driven by AM symbiosis diversity [e.g. 20]. Thus, AM fungi constitute a key compartment of soil fertility. The plant can be colonized by a variety of AM fungi (i.e., no host-specificity). However, the recent findings suggest that plants can choose to reward and enroll some fungal colonizers in order to ensure access to particular functions related to their needs [17]. This selective rewarding is likely to lead to the exclusion of certain colonizers and culminate in an observed 'host-plant preference' e.g. [21;22].

This leads to the idea that a plant can filter soil AM fungi depending on its requirements, the season and location. Conventional field-based agriculture makes use of very limited crop plant diversity, fungicides, soil tillage and 
162 fertilizer. The pressure exerted by agricultural practices leads to a reduction in

163 AM fungal diversity compared to more natural ecosystems e.g. [23;24].

164 Breeders generally select crop cultivars from rich soils which have been under

165 conventional agriculture for many years. In fact, the ultimate result of this 166 selection strategy is to produce a plant that is best adapted to current 167 agricultural practices and the related agrosystems anthropization. Agricultural 168 soils have been enriched with fertilizers for decades and the ecological function 169 of AM fungi as plant phosphorus providers is less important in these enriched 170 soils. This, together with the breeding trajectory, will have relaxed the plant 171 sanction trait in modern crops, as is the case in soybean (Glycine max (L.) 172 Merr.) where ancient varieties are better able to control Rhizobia cheaters than 173 modern ones [18]. From an interesting meta-analysis performed from 39 174 publications it appears that there is '...no evidence that new crops plant 175 genotypes lost their ability to respond to mycorrhiza due to agricultural and 176 breeding practices...' [25]. Two alternative hypotheses for AM symbiosis can be put forward. First, we 178 can hypothesize that the same trend as in the Rhizobium/legume mutualism 179 will have already occurred for AM mutualism with a resulting loss of the 180 sanction trait against AM fungal cheaters. As a consequence, an increase in AM 181 fungal cheaters can be expected in agricultural soils. Because AM fungi 182 constitute a fundamental component of soil fertility, solutions for a more 183 ecologically intensive agriculture should focus on this compartment (Box 2.). 184 Plant breeders could also imagine new selection trajectories where the sanction 185 trait is considered as a major selection target (i.e. the capacity of plants to 186 punish bad cooperators by a carbon embargo [17]). In this way the possibilities 
187 offered by AM functional efficiency could be restored and agricultural practices 188 modified by reducing soil inputs and tillage (Box 2). The alternative hypothesis 189 is that plant breeders have selected cultivars that are very efficient for mineral 190 foraging through soil AM fungal mutualists. This apparently optimistic 191 hypothesis is worse than that of a loss of the sanction trait in crops, because of 192 the lack of long term sustainability. Furthermore, one important component of 193 soil fertilizer, phosphorus, is known to rely on high quality rock phosphate, 194 which is a finite resource. More than $85 \%$ of the global phosphate resources are 195 dominated by only 3 countries which is far fewer than the number of countries 196 controlling the world's oil reserves [26]. Phosphorus (P) supply is thus of 197 strategic importance for many countries, and “...many food producers are in 198 danger of becoming completely dependent on this trade..." [26]. Major 199 agricultural regions such as India, America, and Europe are already dependent 200 on $\mathrm{P}$ imports. Phosphate market prices can soar, as shown by the $700 \%$ 201 increase in 2008 [26], especially as phosphate mining production is predicted 202 to attain a peak in 2030 [27].

Other plant mutualisms, in addition to arbuscular mycorrhiza, should potentially have a synergistic impact on plant productivity and plant resistance against stresses (Box 2). For example, infection of barley (Hordeum vulgare) with an endophytic fungus, Piriformosa indica, increases resistance to stresses 208 including salinity and systemic resistance of the crop to root and leaf pathogens, and a concomitant increase in yield production [28]. Native plants in coastal environments and geothermal habitats require fungal endophytes in order to grow [29]. Thus a passive adaptation of the plant is observed, with the 
212 endophytic fungus providing a selective advantage to the colonized plant.

213 Infection of the tomato (Solanum lycopersicum) plant with these endophytes,

214 for example, confers salt or heat resistance [29]. It can thus be argued that 215 solutions, which support a more productive and sustainable agriculture and 216 involve the use of endophytic microorganisms, do exist but have as yet been 217 little explored.

219 Concluding remarks

220 The Green Revolution that started about 50 years ago, allowed food shortages 221 to be limited. Given the stocks of resources and human population growth, this 222 Green Revolution can continue for only a few more decades. The counterpart of 223 this Green Revolution is a high cost to the environment and global 224 environmental changes [4]. If nothing is done to counteract these changes, 225 thresholds will be exceeded, with dramatic consequences [3] and indeed the 226 impossibility for natural ecosystems to regenerate. A more sustainable 227 agriculture and a plant neodomestication has to emerge to guarantee food 228 supply over the next 50 years. One way of achieving a more ecologically 229 intensive agriculture would be to consider and protect the ecological functions 230 displayed by AM fungi, which have been effective for more than 400 million 231 years, whatever the ecosystem. This will not only improve natural plant mineral 232 nutrition but also water supply and other ecological functions that have already 233 been clearly documented [30]. Research efforts must also 234 stimulate/accompany this possible plant neodomestication. 


\section{Acknowledgements}

237 The work is supported by a grant from 'I'Agence Nationale de la Recherche'

238 (ANR-10-STRA-0002). We acknowledge E.T. Kiers and D. Warwick for comments

239 and suggestions of modifications on previous versions of the manuscript. 


\section{Box 1. Arbuscular mycorrhizal symbiosis}

241 Among plant mutualistic symbioses, the arbuscular mycorrhiza relationship has

242 been evolving for more than 400 million years [31]. This symbiosis is really 243 mundane and widespread with approximately $80 \%$ of land plants colonized by

244 AM fungi [30] across a huge diversity of ecosystems. In this symbiosis, plants 245 provide carbohydrates to the arbuscular mycorrhizal fungi in exchange for 246 minerals, drought resistance and protection against pathogens e.g. [30;32]. 247 The fungus in this mutualistic relationship is an obligate biotroph, its 248 transmission is horizontal and there is no genetic uniformity between fungal 249 symbionts. Several different fungal symbionts colonize the same plant roots. 250 


\section{Box 2. Future of agricultural trajectories guidelines}

253 Forests represent important carbon stocks which, when converted into 254 agrosystems, have a huge impact on $\mathrm{CO} 2$ emission to the atmosphere [33] as 255 well as a collateral effect on biodiversity [6;9]. In the context of global changes, 256 it seems fundamental to limit agricultural expansion [10]. The key point seems 257 to be to improve crop yields within existing agrosystems. However, 258 conventional agricultural practices and plant breeding strategies have arguably 259 entered a 'cul-de-sac' because they are “...unlikely to improve attributes 260 already favored by millions of years of natural selection..." [11] while under261 explored natural keys to crop yield improvement, such as AM fungi, exist but 262 are ignored and maltreated.

To maintain or restore this essential component of soil fertility, 264 conventional agricultural practices need to be modified. The following are suggested guidelines to improve the sustainability of human land use and crop 266 productivity:

267 (i) Because AM diversity is positively correlated with plant diversity e.g. [20], 268 agriculture will need to make use of greater plant diversity.

269 (ii) Tillage, if employed, will need to be restricted to maintain hyphal networks 270 and functional efficiency and also to preserve soil aggregates and limit water 271 losses [34].

272 (iii) Plant breeders should select plants in poor soils, taking into account the 273 two previous aspects, the aim being to maximize the efficiency of AM fungi 274 symbiosis (i.e., plants able to take full advantage of the AM fungi available in 
275 soils). These new selected plants might also be able to restore effective AM

276 fungi in the field

277 (iv) Additional mutualist microorganisms such as endophytic fungi should also

278 be considered as important targets to improve plant resistance and 279 productivity.

280

281 This should facilitate a passive promotion of AM fungal mutualism and, at 282 the same time, reduce the use of fertilizers, biocides and water. These 283 guidelines have the potential to enhance crop yields and reduce the problems 284 associated with conventional agriculture in both developed and developing 285 countries.

286

287

288 


\section{References}

2901 Battisti, D.S. and Naylor, R.L. (2009) Historical warnings of future food 291 insecurity with unprecedented seasonal heat. Science 323,240-244

2 Lutz, W. et al. (2001) The end of world population growth. Nature 412, 543-

\section{5}

3 Harte, J. (2007) Human population as a dynamic factor in environmental 295 degradation. Popul. Environ. 28, 223-236

4 Tilman, D. et al. (2001) Forecasting agriculturally driven global environmental change. Science 292,281-284

5 Cirera, X. and Masset, E. (2010) Income distribution trends and future food demand. Phil. Trans. R. Soc. B 365,2821-2834

6 Foley, J.A. et al. (2005) Global consequences of land use. Science 309, 570301

7 Burney, J.A. et al. (2010) Greenhouse gas mitigation by agricultural intensification. Proc. Natl. Acad. Sci. U.S.A. 107,12052-12057

8 Balmford, A. et al. (2012) What conservationists need to know about farming.

Proc. R. Soc. B. $279,2714-2724$

9 Nelson, E. et al. (2010) Projecting global land-use change and its effect on ecosystem service provision and biodiversity with simple models. PloS ONE 5, e14327 doi:10.1371/journal.pone.0014327 (http://www.plosone.org/)

10 Foley, J.A. et al. (2011) Solution for a cultivated planet. Nature 478, 337-342

11 Weiner, J. et al. (2010) Evolutionary agroecology, the potential for cooperative, high density, weed-suppressing cereals. Evol. Appl. 3,473-479 
31212 Marx, J. (2004) The roots of plant-microbe collaborations. Science 304, 234$313 \quad 236$

31413 Verbruggen, E. and Kiers E.T. (2010) Evolutionary ecology of mycorrhizal 315 functional diversity in agricultural systems. Evol. Appl. 3,547-560

31614 Johnson, N.C. et al. (2010) Resource limitation is a driver of local adaptation 317

16 Egerton-Warburton, L.M. et al. (2007) Mycorrhizal community dynamics

15 Johnson, N.C. (1993) Can fertilization of soil select less mutualistic mycorrhizae. Ecol. Appl. 3, 749-757

following nitrogen fertilization, a cross-site test in five grasslands. Ecol.

$$
\text { Monogr. 77, 527-544 }
$$

17 Kiers, E.T. et al. (2011) Reciprocal rewards stabilize cooperation in the mycorrhizal symbiosis. Science 333, 880-882

18 Kiers, E.T. et al. (2007) Human selection and the relaxation of legume defences against ineffective rhizobia. Proc. Natl. Acad. Sci. U.S.A. 274,31193126

19 Smith, S.E. et al. (2003) Mycorrhizal fungi can dominate phosphate supply to plants irrespective of growth responses. Plant Physiol. 133, 16-20

20 van der Heijden, M.G.A. et al. (1998) Mycorrhizal fungal diversity determines plant biodiversity, ecosystem variability and productivity. Nature 396, 69-72

21 Vandenkoornhuyse, P. et al. (2002) Arbuscular mycorrhizal community composition associated with two plant species in a grassland ecosystem. Mol. Ecol. 11,1555-1564 
33522 Vandenkoornhuyse, P. et al. (2003) Co-existing grass species have 336 distinctive arbuscular mycorrhizal communities. Mol. Ecol. 12, 3085-3095

33723 Helgason, T. et al. (1998) Ploughing up the wood-wide web? Nature 394,431.

33824 Verbruggen, E. et al. (2010) Positive effects of organic farming on below339 ground mutualists, large-scale comparison of mycorrhizal fungal 340 communities in agricultural soils. New Phytol. 186, 968-979

25 Lehman, A. et al. (2012) Mycorrhizal responsiveness trends in annual crop plants and their wild relatives - a meta-analysis on studies from 1981 to 2010. Plant Soil 355, 231-250.

26 Elser, J. and Bennett, E. (2011) A broken biogeochemical cycle. Nature $478,29-31$

27 Cordell, D. et al. (2009) The story of phosphorus, global food security and 348 food for thought. Global Environ. Chang. 19, 292-305

28 Waller, F. et al. (2005) The endophytic fungus Piriformospora indica reprograms barley to salt-stress tolerance,disease resistance, and higher

30 Smith, S. and Read, D. (2008) Mycorrhizal Symbiosis, Edition 3. Academic Press and Elsevier London ISBN 978-0-12-370526-6

31 Redecker, D. et al. (2000) Glomalean fungi from the Ordovician. Science 289, 1920-1921 
35832 Smith, S.E. et al. (2010) Plant performance in stressful environments, 359 interpreting new and established knowledge of the roles of arbuscular 360 mycorrhizas. Plant Soil 326, 3-20

36133 Aldhous, P. (2004) Land remediation: Borneo is burning. Nature 432, 144$362 \quad 146$

36334 De Souza Andrade, D. et al. (2003) Long-term effects of agricultural 364 practices on microbial community. In Conservation agriculture. (García365 Torres, L. et al. eds.), pp. 301-306 Kluwer Academic Publishers, Dordrecht, $366 \quad$ Netherlands 


\section{Figure 1}

369 Hyphal network of arbuscular mycorrhiza. This dense network propagated from

370 the plant roots explores a high volume of soil and capture mineral nutrients and

371 water which are transfered to the roots to the benefit of the host-plant. In

372 return host-plant provides photosynthesized sugars and polylosides to sustain

373 the mutualistic fungal compartment.

374 